\title{
Photocatalytic Mineralization of Organic Acids over Visible-Light-Driven $\mathrm{Au} / \mathrm{BiVO}_{4}$ Photocatalyst
}

\author{
Kanlaya Pingmuang, ${ }^{1}$ Natda Wetchakun, ${ }^{2,3}$ Wiyong Kangwansupamonkon, ${ }^{4}$ \\ Kontad Ounnunkad, ${ }^{1,5}$ Burapat Inceesungvorn, ${ }^{1,5}$ and Sukon Phanichphant ${ }^{2}$ \\ ${ }^{1}$ Nanoscience Research Laboratory and Department of Chemistry, Faculty of Science, Chiang Mai University, \\ Chiang Mai 50200, Thailand \\ ${ }^{2}$ Materials Science Research Center, Faculty of Science, Chiang Mai University, Chiang Mai 50200, Thailand \\ ${ }^{3}$ Department of Physics and Materials Science, Faculty of Science, Chiang Mai University, Chiang Mai 50200, Thailand \\ ${ }^{4}$ National Nanotechnology Center, Thailand Science Park, Paholyothin Road, Klong 1, Klong Luang, Phathumthani 12120, Thailand \\ ${ }^{5}$ NANOTEC Center of Excellence, Chiang Mai University, Chiang Mai 50200, Thailand
}

Correspondence should be addressed to Sukon Phanichphant; sphanichphant@yahoo.com

Received 31 October 2012; Revised 3 May 2013; Accepted 7 May 2013

Academic Editor: Vincenzo Augugliaro

Copyright (C) 2013 Kanlaya Pingmuang et al. This is an open access article distributed under the Creative Commons Attribution License, which permits unrestricted use, distribution, and reproduction in any medium, provided the original work is properly cited.

\begin{abstract}
$\mathrm{Au} / \mathrm{BiVO}_{4}$ visible-light-driven photocatalysts were synthesized by coprecipitation method in the presence of sodium dodecyl benzene sulfonate (SDBS) as a dispersant. Physical characterization of the obtained materials was carried out by X-ray diffraction (XRD), scanning electron microscopy (SEM), energy dispersive X-ray spectroscopy (EDX), UV-Vis diffuse reflectance spectroscopy (DRS) and Brunauer, and Emmett and Teller (BET) specific surface area measurement. Photocatalytic performances of the asprepared $\mathrm{Au} / \mathrm{BiVO}_{4}$ have also been evaluated via mineralizations of oxalic acid and malonic acid under visible light irradiation. XRD and SEM results indicated that $\mathrm{Au} / \mathrm{BiVO}_{4}$ photocatalysts were of almost spherical particles with scheelite-monoclinic phase. Photocatalytic results showed that all $\mathrm{Au} / \mathrm{BiVO}_{4}$ samples exhibited higher oxalic acid mineralization rate than that of pure $\mathrm{BiVO}$, probably due to a decrease of $\mathrm{BiVO}_{4}$ band gap energy and the presence of surface plasmon absorption upon loading $\mathrm{BiVO}_{4}$ with $\mathrm{Au}$ as evidenced from UV-Vis DRS results. The nominal Au loading amount of $0.25 \mathrm{~mol} \%$ provided the highest pseudo-first-order rate constant of $0.0487 \mathrm{~min}^{-1}$ and $0.0082 \mathrm{~min}^{-1}$ for degradations of oxalic acid $\left(\mathrm{C}_{2}\right)$ and malonic acid $\left(\mathrm{C}_{3}\right)$, respectively. By considering structures of the two acids, lower pseudo-first-order rate constantly obtained in the case of malonic acid degradation was likely due to an increased complexity of the degradation mechanism of the longer chain acid.
\end{abstract}

\section{Introduction}

In the past few years, interest has been paid to research on water remediation with the application of an ideal "green" technology known as semiconductor photocatalysis. It has been widely accepted that this process successfully combines the principle of heterogeneous catalysis with a utilization of solar energy. By using this photocatalytic process, degradation of a wide range of organic pollutants into harmless carbon dioxide and water is made possible. Titanium dioxide, a well-known UV-light-active photocatalyst, has demonstrated an outstanding photocatalytic performance on degradation of various organic compounds [1-3]. However, with its wide band gap energy of $3.2 \mathrm{eV}$, the application of $\mathrm{TiO}_{2}$ is limited to UV light region which accounts for only $4 \%$ of the whole solar energy [4]. Therefore, extensive research has currently been devoted to the development of visible-light-driven catalyst in order to effectively utilize the vast majority of the solar energy [4-6]. Bismuth vanadate $\left(\mathrm{BiVO}_{4}\right)$ has long been recognized for its ferroelasticity [7] and its application as a nontoxic and bright yellow pigment [8]. It has also been used as a gas sensing semiconductor, solid-state electrolyte, and cathode material in solid oxide fuel cells, and has recently been proved to be an active visible-light-responsive photocatalyst for water splitting [9] and organic pollutant decomposition $[10,11]$. Since $\mathrm{BiVO}_{4}$ is stable and neutral in water 
without altering the solution $\mathrm{pH}$, its application as photocatalyst for environmental treatment is extensively investigated. The photocatalytic property of $\mathrm{BiVO}_{4}$ is strongly dependent on its morphology and crystalline form [12-14]. Generally, synthetic $\mathrm{BiVO}_{4}$ was found to exist in three crystalline phases including scheelite-monoclinic type, scheelitetetragonal type, and zircon-tetragonal type [15]. Among the three polymorphs, the scheelite-monoclinic structure with band gap energy of $2.4 \mathrm{eV}$ is reported to possess the highest photocatalytic activity $[4,13,16]$. Therefore, many synthesis methods have been focused on the selective preparation of scheelite-monoclinic $\mathrm{BiVO}_{4}$ photocatalyst.

Different synthetic routes have previously been employed to prepare the scheelite-monoclinic $\mathrm{BiVO}_{4}$ such as traditional solid-state reaction [17] and hydrothermal method [18]. However, these strategies have encountered similar problem in which the obtained $\mathrm{BiVO}_{4}$ possessed very low surface area, normally in the range of less than $10 \mathrm{~m}^{2} \mathrm{~g}^{-1}$ and, as a consequence, low photocatalytic performance has usually been attained. Apart from the low surface area of $\mathrm{BiVO}_{4}$, difficult separation of photogenerated electronhole pair was also reported to be one of the main reasons accounting for its poor photocatalytic efficiency [12, 19]. However, by loading $\mathrm{BiVO}_{4}$ with only small amount of metals such as Pt [11], Au [12] Pd [19], Ag, Co, and Ni [20], enhanced photocatalytic activity was achieved possibly due to the metals acting as electron traps, thus promoting electron-hole separation and the interfacial charge-transfer process from catalyst to adsorbed substrate $[12,19,20]$. However, there are few reports on the development of $\mathrm{Au} / \mathrm{BiVO}_{4}$ composite to affect photocatalysis under visiblelight irradiation. Recently, Cao et al. [21] reported that the $\mathrm{Au} / \mathrm{BiVO}_{4}$ composite showed superior visible-light activities in decomposing methyl orange dye. However, Long et al. [22] synthesized $\mathrm{Au} / \mathrm{BiVO}_{4}$ composite photocatalysts and found that the photocatalysts exhibited enhanced visiblelight photocatalytic activities on degradation of phenol. Since dicarboxylic acids are generally observed as intermediate products in the degradation pathways of various organic pollutants in real wastewaters [23-25], the influence of mutual interactions on the photocatalytic conversion process needs to be investigated. However, there has been no report that demonstrates the simultaneous detoxification of the dicarboxylic acids by $\mathrm{Au} / \mathrm{BiVO}_{4}$ composite. Herein, we report the preparation and photocatalytic performance of a visiblelight-driven $\mathrm{Au} / \mathrm{BiVO}_{4}$ catalyst. $\mathrm{BiVO}_{4}$ with the scheelitemonoclinic structure was prepared by surfactant-assisted coprecipitation method and then subsequently impregnated with $\mathrm{HAuCl}_{4}$ solution to finally obtain $\mathrm{Au} / \mathrm{BiVO}_{4}$. Photocatalytic performances of the as-prepared scheelite-monoclinic $\mathrm{Au} / \mathrm{BiVO}_{4}$ samples were evaluated through the mineralizations of oxalic acid and malonic acid under visible light irradiation.

\section{Experimental}

2.1. Synthesis of $\mathrm{Au} / \mathrm{BiVO}_{4}$. Bismuth nitrate pentahydrate $\left(\mathrm{Bi}\left(\mathrm{NO}_{3}\right)_{3} \cdot 5 \mathrm{H}_{2} \mathrm{O}, 99 \%\right.$, Ajax) and ammonium vanadate
$\left(\mathrm{NH}_{3} \mathrm{VO}_{4}, 99 \%\right.$, Carlo) were used as bismuth and vanadium precursors. Sodium dodecylbenzene sulfonate $\left(\mathrm{C}_{18} \mathrm{H}_{29} \mathrm{SO}_{3} \mathrm{Na}\right.$ (SDBS), 98\%, Aldrich), an anionic surfactant, was employed as a dispersant in this study. All chemicals were used as received without further purification. Firstly, $0.125 \mathrm{M}$ each of $\mathrm{Bi}$ and $\mathrm{V}$ were separately prepared by dissolving $\mathrm{Bi}\left(\mathrm{NO}_{3}\right)_{3} \cdot 5 \mathrm{H}_{2} \mathrm{O}$ in $4.0 \mathrm{M}$ nitric acid solution and $\mathrm{NH}_{3} \mathrm{VO}_{4}$ in $4.0 \mathrm{M}$ ammonia solution. The as-prepared bismuth nitrate solution was then mixed with $0.1 \mathrm{M}$ SDBS in ethanol. To this mixture, the vanadium precursor solution was slowly added and the solution was kept under stirring for $30 \mathrm{~min}$. Then 4.0 $\mathrm{M}$ ammonia solution used as a precipitant was added drop-wise until $\mathrm{pH} 7$ was attained. The resultant precipitate was washed with deionized water, centrifuged, and dried at $60^{\circ} \mathrm{C}$ for $12 \mathrm{~h}$. The dried powder was then calcined at $400^{\circ} \mathrm{C}$ for $2 \mathrm{~h}$ to obtain $\mathrm{BiVO}_{4}$ sample. The as-prepared $\mathrm{BiVO}_{4}$ sample was then impregnated with aqueous solution of gold chloride $\left(\mathrm{HAuCl}_{4} \cdot 2 \mathrm{H}_{2} \mathrm{O}, \leq 48 \%\right.$ Aldrich) containing the nominal gold amounts of $0.10,0.25,0.50,0.75$, and $1.00 \mathrm{~mol} \%$. Then the impregnated powder was dried at $60^{\circ} \mathrm{C}$ for $3 \mathrm{~h}$ and subsequently calcined at $350^{\circ} \mathrm{C}$ for $2 \mathrm{~h}$ to finally obtain $\mathrm{Au} / \mathrm{BiVO}_{4}$.

2.2. Characterization. Powder X-ray diffraction (XRD) measurement was performed on an X-ray diffractometer (JEOL, JDX-3530) using $\mathrm{Cu} \mathrm{K} \alpha$ radiation $(\lambda=1.5418 \AA)$ and scanning from $10^{\circ}$ to $75^{\circ}$. Specific surface area (SSA) of the particles was measured on Beckman Coulter SA 3100 according to the Brunauer-Emmett-Teller (BET) method. UV-Vis diffuse reflectance spectra were obtained on a UV-Vis spectrometer (PerkinElmer, Lambda 650S) using $\mathrm{MgO}$ as a reference and were converted to absorbance by Kubelka-Munk method [26]. Particle morphology and chemical composition were also investigated on a scanning electron microscope (Hitachi, S3400N) equipped with an energy dispersive X-ray spectrophotometer (Oxford, ISIS300).

2.3. Photocatalytic Activity. Visible light photocatalytic activities of the as-prepared $\mathrm{Au} / \mathrm{BiVO}_{4}$ powders were evaluated by the mineralization of oxalic acid $(0.208 \mathrm{mM})$ and malonic acid $(0.139 \mathrm{mM})$ in aqueous solution at ambient temperature and pressure. The photocatalytic studies were performed using a $100 \mathrm{~mL}$ spiral photoreactor equipped with a fluorescent lamp (Davis 33 cool white, $18 \mathrm{~W}$, intensity of $4.39 \mathrm{~mW} / \mathrm{m}^{2}$ ), filtered with double-layer of Rosco E-colour UV filter to remove any UV component $(\lambda<400 \mathrm{~nm})$, in the middle of the reactor. Typically, $50 \mathrm{~mL}$ of $1.0 \mathrm{~g} \mathrm{~L}^{-1}$ catalyst suspension was prepared by dispersing the predetermined amount of catalyst in deionized water with ultrasonic probe for $15 \mathrm{~min}$. The suspension $\mathrm{pH}$ was then adjusted to $3.0 \pm$ 0.1 using $1 \mathrm{M}$ perchloric acid solution before charging into the spiral reactor. Prior to catalytic testing, adsorbed carbon contaminants on the catalyst surface were firstly removed by illuminating the catalyst suspension with UV light for 1 h. Photocatalytic mineralizations of oxalic acid and malonic acid were then carried out by injecting $100 \mu \mathrm{L}$ of organic compound solution containing $500 \mu \mathrm{g}$ of carbon. Adsorption/desorption equilibrium of the organic substrates on the 


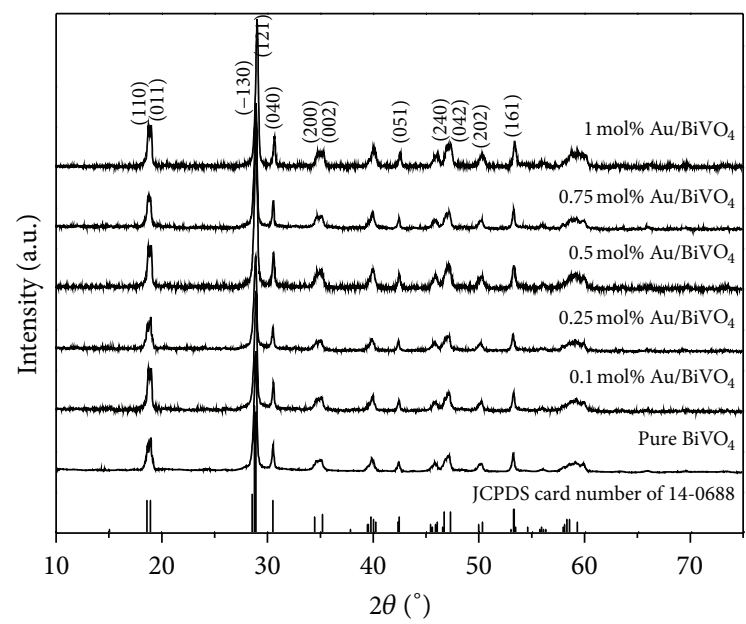

FIGURE 1: XRD patterns of pure $\mathrm{BiVO}_{4}$ and $\mathrm{Au} / \mathrm{BiVO}_{4}$ with different Au loading amounts.

catalyst surface was attained by circulating the suspension for 30 min under the dark. Then the system was irradiated and the photocatalytic reaction was initiated. Dissolved carbon dioxide $\left(\mathrm{CO}_{2}\right)$ in water, generated from dicarboxylic acid, could be detected by online conductivity meter (Eutech 5000) as described by Abdullah et al. [27].

\section{Results and Discussion}

3.1. Physical Property of $\mathrm{Au} / \mathrm{BiVO}_{4}$. Figure 1 illustrates XRD diffraction patterns of pure $\mathrm{BiVO}_{4}$ and $\mathrm{Au} / \mathrm{BiVO}_{4}$ with different $\mathrm{Au}$ loading amounts. The XRD patterns revealed sharp peaks, indicating high crystallinity of the obtained particles. XRD patterns of all samples presented similar profiles and the diffraction peaks matched well with scheelite-monoclinic $\mathrm{BiVO}_{4}$ (JCPDS file no. 14-0688). However, these obtained samples are not well-distorted scheelite-monoclinic $\mathrm{BiVO}_{4}$ because there is no peak at $15^{\circ}$ of $2 \theta$ and the peaks at $18.5^{\circ}$, $35^{\circ}$ and $46^{\circ}$ of $2 \theta$ are not well split [28].

Results from XRD suggested that the scheelite-monoclinic $\mathrm{BiVO}_{4}$, although with less distortion, was selectively prepared by using SDBS-assisted coprecipitation method. Upon loading pure $\mathrm{BiVO}_{4}$ with $\mathrm{Au}$, no significant change in diffraction patterns was observed which suggested that loading with Au up to $1.0 \mathrm{~mol} \%$ did not affect the crystal structure of scheelite-monoclinic $\mathrm{BiVO}_{4}$. No other peak due to $\mathrm{Au}$ metal was found possib because the Au loading amount was small and high dispersion of Au was obtained as supported by EDX spectra in Figures 2(d) and 2(f) [29]. BET specific surface area (SSA) of the resulted $\mathrm{BiVO}_{4}$ was about $23 \mathrm{~m}^{2} \mathrm{~g}$. Upon loading the obtained $\mathrm{BiVO}_{4}$ with $\mathrm{Au}$ from 0.1$1.0 \mathrm{~mol} \%$, SSA of the sample was gradually increased from $23 \mathrm{~m}^{2} \mathrm{~g}^{-1}$ to $31 \mathrm{~m}^{2} \mathrm{~g}^{-1}$.

Morphologies of pure $\mathrm{BiVO}_{4}, 0.25 \mathrm{~mol} \% \mathrm{Au} / \mathrm{BiVO}_{4}$, and $1.0 \mathrm{~mol} \% \mathrm{Au} / \mathrm{BiVO}_{4}$ as well as the presence of $\mathrm{Au}$ on the surface of $\mathrm{Au} / \mathrm{BiVO}_{4}$ samples were studied by SEM and EDX as illustrated in Figure 2. As seen from the SEM images in Figures 2(a), 2(c), and 2(e), pure $\mathrm{BiVO}_{4}, 0.25 \mathrm{~mol} \% \mathrm{Au} / \mathrm{BiVO}_{4}$,
TABLE 1: The content of synthesized pure $\mathrm{BiVO}_{4}$ and different $\mathrm{Au} / \mathrm{BiVO}_{4}$ powders determined by EDX analysis.

\begin{tabular}{lcccc}
\hline \multirow{2}{*}{ Samples } & \multicolumn{4}{c}{ Element (at.\%) } \\
& $\mathrm{O}$ & $\mathrm{V}$ & $\mathrm{Bi}$ & $\mathrm{Au}$ \\
\hline Unloaded $\mathrm{BiVO}_{4}$ & 78.37 & 11.67 & 9.96 & - \\
0.25 at\% $\mathrm{Au} / \mathrm{BiVO}_{4}$ & 79.63 & 11.15 & 9.11 & 0.12 \\
$1.0 \mathrm{at} \% \mathrm{Au} / \mathrm{BiVO}_{4}$ & 83.08 & 9.01 & 7.60 & 0.31 \\
\hline
\end{tabular}

and $1.0 \mathrm{~mol} \% \mathrm{Au} / \mathrm{BiVO}_{4}$ were formed in an almost irregular morphology with the particle size in the range of 300$800 \mathrm{~nm}$. No significant change in terms of $\mathrm{BiVO}_{4}$ particle size was observed upon loading pure $\mathrm{BiVO}_{4}$ with 0.25 or $1.0 \mathrm{~mol} \%$ of $\mathrm{Au}$. The existence of $\mathrm{Au}$ in $0.25 \mathrm{~mol} \% \mathrm{Au} / \mathrm{BiVO}_{4}$ sample was not clearly observed from the EDX spectrum (Figure 2(e)); however, the peak due to Au metal was clearly seen from the nominal $1.0 \mathrm{~mol} \% \mathrm{Au} / \mathrm{BiVO}_{4}$ as shown in Figure 2(f). The atomic percentage of each element is given in Table 1. The amount of Au in both samples was less than the loading amount since the Au nanoparticles were not evenly distributed on the $\mathrm{BiVO}_{4}$ support; therefore, the selected areas had less amounts than the actual amounts.

3.2. Optical Absorption Behavior. The inset of Figure 3(a) indicated that pure $\mathrm{BiVO}_{4}$ had no absorption in the region of $550-800 \mathrm{~nm}$; however, all $\mathrm{Au} / \mathrm{BiVO}_{4}$ samples showed enhanced absorption in this region upon increasing $\mathrm{Au}$ content. The absorption in this range can be ascribed to the surface plasmon resonance (SPR) of Au nanoparticles which is attributed to a collective of conduction electrons in response to optical excitation [30]. In addition, the SPR peak was slightly shifted to longer wavelength as increasing $\mathrm{Au}$ content, possibly due to an increase of Au particle size [31]. Optical absorption near the band edge $\alpha$ and $h v$ represent, a constant, absorption coefficient and the incident photon energy, respectively $[4,32]$. The $n$ value depends on the characteristics of the electron transition in a semiconductor. Since the electron transition in $\mathrm{BiVO}_{4}$ is a direct transition, the value of $n=1[4,19,32,33]$. The band gaps were estimated $(h \nu)$ by using the intercept of the tangent to the $X$-axis as illustrated in Figure 3(b). The estimated band gap energy of pure $\mathrm{BiVO}_{4}$ was $2.53 \mathrm{eV}$. However, upon loading $\mathrm{BiVO}_{4}$ with the nominal gold amount of $0.1-1.0 \mathrm{~mol} \%$, a small shift towards lower band gap energy in the range of $2.48-2.50 \mathrm{eV}$ was observed, probably due to a charge-transfer transition between $\mathrm{Au}$ and $\mathrm{BiVO}_{4}[12]$.

3.3. Photocatalytic Property. Photocatalytic activities of scheelite-monoclinic $\mathrm{BiVO}_{4}$ and $\mathrm{Au} / \mathrm{BiVO}_{4}$ were evaluated by studying the mineralizations of two model organic compounds which were oxalic acid and malonic acid in aqueous solution under visible light illumination. Photocatalytic mineralizations of oxalic acid and malonic acid over the asprepared $\mathrm{Au} / \mathrm{BiVO}_{4}$ as a function of irradiation time are shown in Figures 4(a) and 4(b), respectively.

Results from Figure 4(a) also indicated that a remarkable photocatalytic performance was obtained from $0.25 \mathrm{~mol} \%$ 


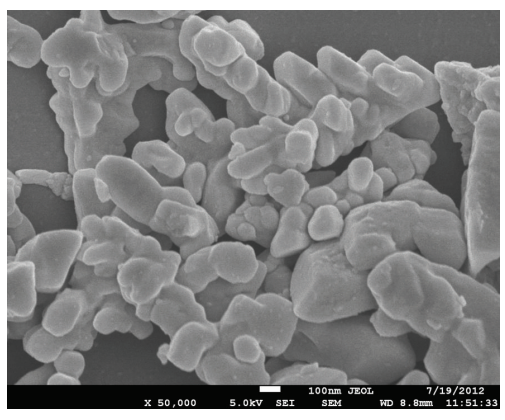

(a)

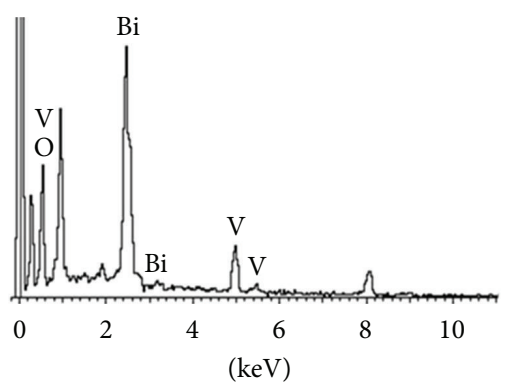

(b)

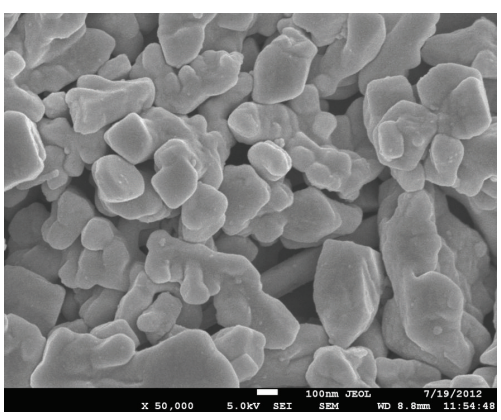

(c)

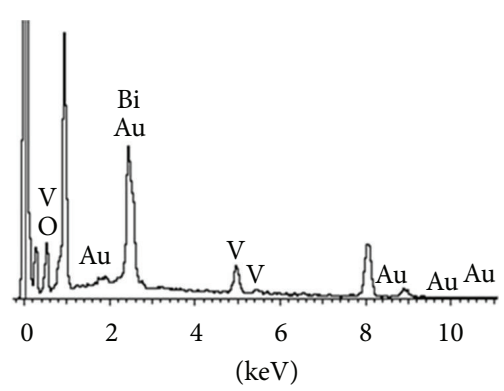

(d)

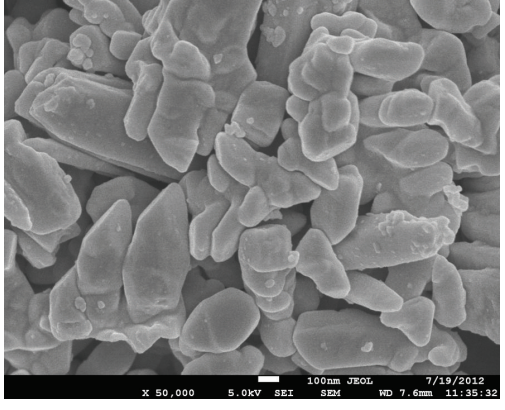

(e)

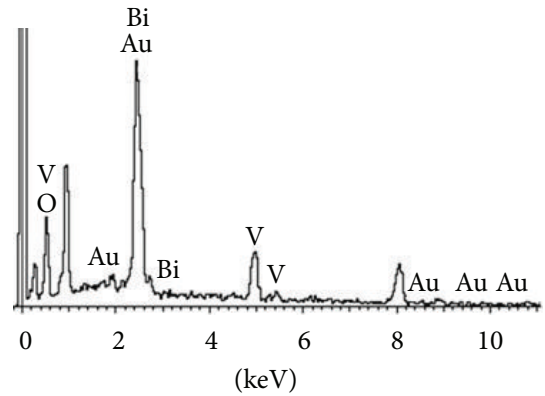

(f)

Figure 2: SEM images and EDX spectra of (a)-(b) pure $\mathrm{BiVO}_{4}$, (c)-(d) $0.25 \mathrm{~mol} \% \mathrm{Au} / \mathrm{BiVO}_{4}$, and (e)-(f) $1.0 \mathrm{~mol} \% \mathrm{Au} / \mathrm{BiVO}{ }_{4}$ samples, respectively.

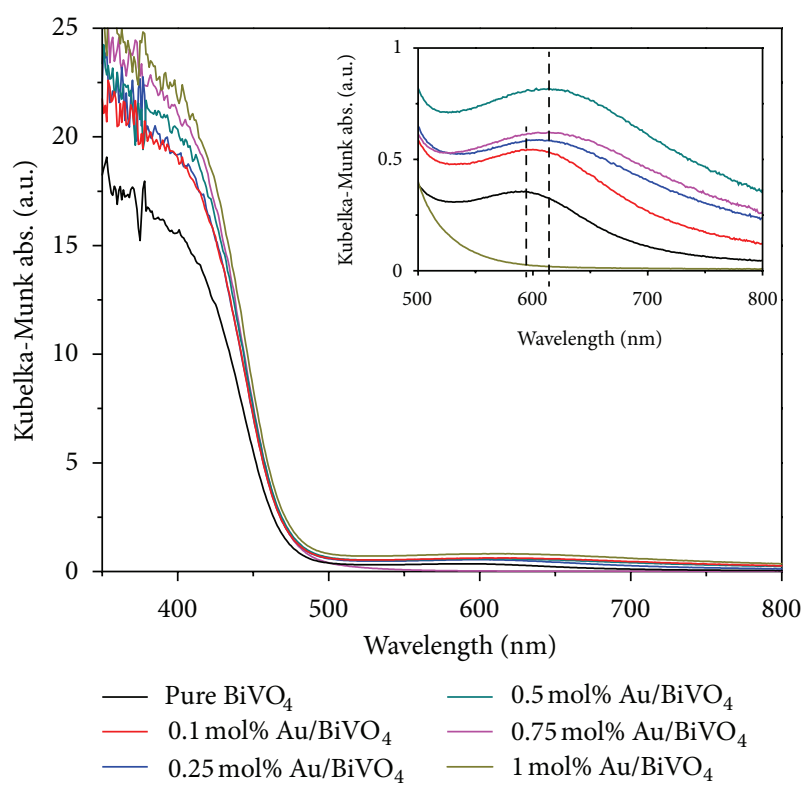

(a)

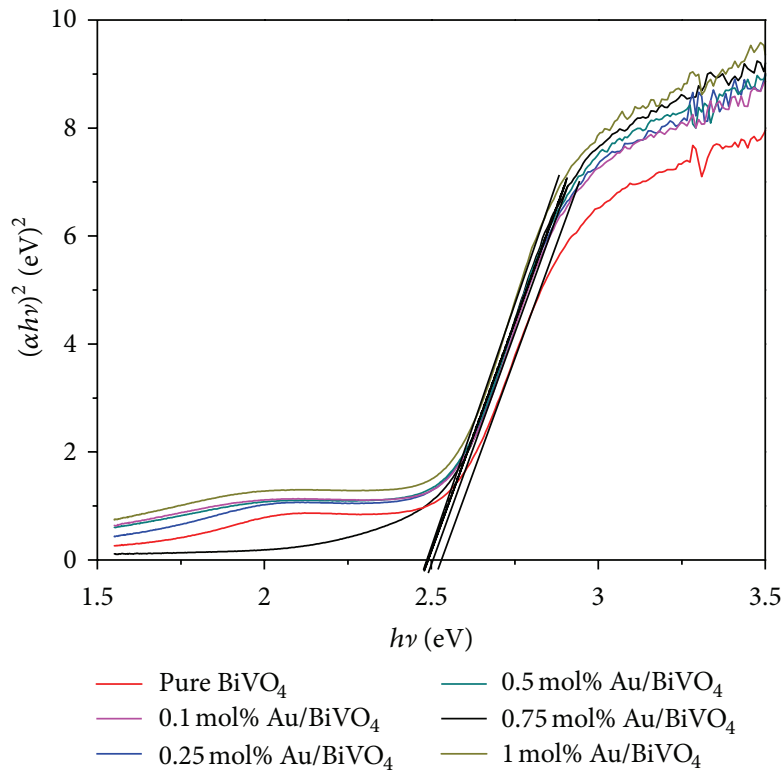

(b)

Figure 3: (a) UV-Vis diffuse absorption spectra of pure $\mathrm{BiVO}_{4}$ and $\mathrm{Au} / \mathrm{BiVO}_{4}$ with an inset showing an enlarged image of the absorption in the range of $500-800 \mathrm{~nm}$ and (b) the plots of $(\alpha h \nu)^{2}$ versus photon energy $(h \nu)$.

$\mathrm{Au} / \mathrm{BiVO}_{4}$. Further loading of Au more than $0.25 \mathrm{~mol} \%$ resulted in a decreased photocatalytic activity. Therefore, an optimum Au loading amount in this study is $0.25 \mathrm{~mol} \%$. The existence of an optimum dopant concentration was previously explained by Zhang et al. [34]. Therein, the author proposed that, at low dopant concentration, metal ion dopant can act as a trap for both electron and hole which then leads to a lengthening in the lifetime of the generated charge carriers and thus resulting in enhanced photocatalytic efficiency. However, at high dopant concentration, the charge trapping 


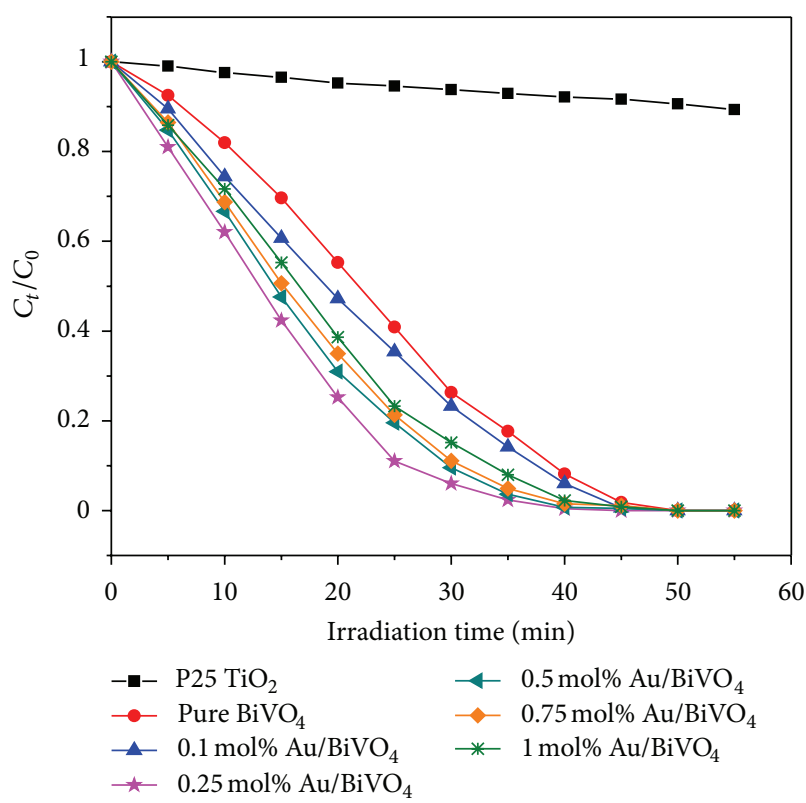

(a)

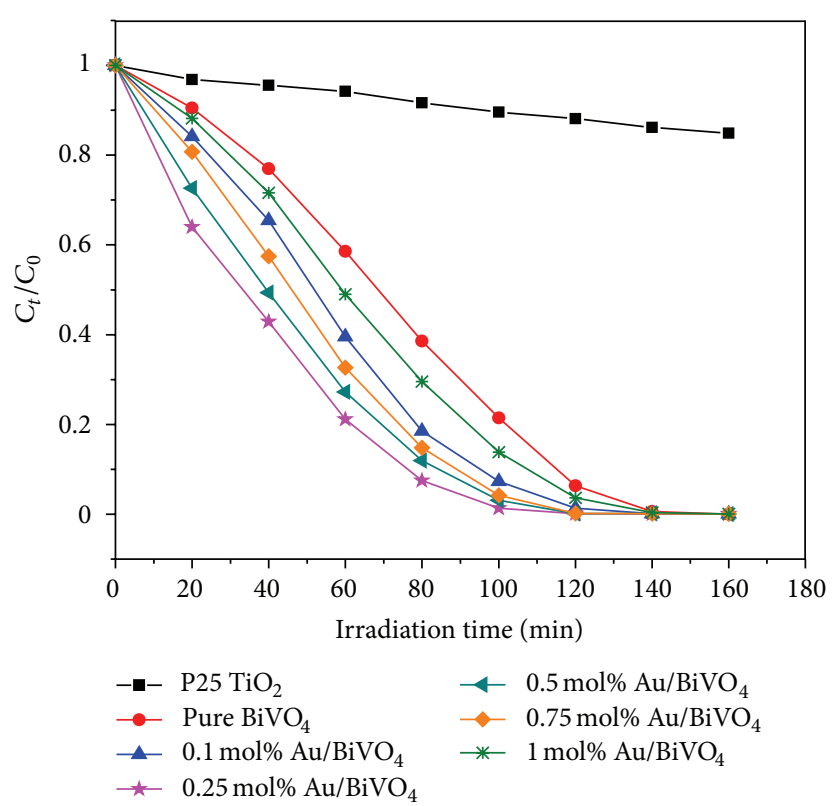

(b)

Figure 4: (a) Photocatalytic mineralization of (a) oxalic acid and (b) malonic acid over $\mathrm{P} 25 \mathrm{TiO}_{2}$, pure $\mathrm{BiVO}_{4}$, and different Au loaded on $\mathrm{BiVO}_{4}$ catalysts.

is high and as such, the charge carrier recombination through quantum tunneling is highly possible $[34,35]$. Therefore, there exists an optimum dopant concentration. A comparison between Figures 4(a) and 4(b) indicated that longer irradiation time was required for malonic acid to attain complete mineralization. This is probably due to the longer hydrocarbon chain length of malonic acid compared with that of oxalic acid.

Photocatalytic mineralization rates of oxalic acid and malonic acid over $0.25 \mathrm{~mol} \% \mathrm{Au} / \mathrm{BiVO}_{4}$ were investigated and presented in Figure 4(b). The obtained results were found to fit well with Langmuir-Hinshelwood (LH) kinetics as evidenced by high correlation coefficient values $\left(R^{2}\right)$ of 0.99 and 0.94 for degradations of oxalic acid and malonic acid, respectively.

The LH kinetic expression is given by $[36,37]$

$$
r=-\left(\frac{d C}{d t}\right)=\frac{k K C}{(1+K C)}
$$

where $r$ represents the initial mineralization rate of organic substrate, $C$ is the concentration of the substrate at an illumination time $t$, and $k$ and $K$ are the mineralization rate constant and the adsorption coefficient of the reactant, respectively. Integration of (1) yields (2):

$$
\ln \left(\frac{C_{0}}{C_{t}}\right)+K\left(C_{0}-C_{t}\right)=k K t
$$

where $C_{0}$ is the initial concentration of the organic substrate and $C_{t}$ in the concentration of the substrate at time $t$. When $C_{0}$ is very small, (2) can be reduced to (3),

$$
\ln \left(\frac{C_{0}}{C_{t}}\right)=k K t=k_{\text {app }} t,
$$

where $k_{\text {app }}$ is the initial apparent rate constant of a pseudofirst-order reaction. By plotting $\ln \left(C_{0} / C_{t}\right)$ versus $t$ as shown in Figure $4(\mathrm{~b}), k_{\text {app }}$ values for photocatalytic mineralizations of oxalic acid over pure $\mathrm{BiVO}_{4}, 0.25 \mathrm{~mol} \% \mathrm{Au} / \mathrm{BiVO}_{4}$ and malonic acid over $0.25 \mathrm{~mol} \% \mathrm{Au} / \mathrm{BiVO}_{4}$ can be obtained from slopes of the graphs. Good regression coefficients observed in this work indicated that the kinetics of dicarboxylic acid mineralizations followed a simplified Langmuir-Hinshelwood rate equation (3) with the pseudo-first order rate constants for oxalic acid degradation over pure $\mathrm{BiVO}_{4}$ and $0.25 \mathrm{~mol} \%$ $\mathrm{Au} / \mathrm{BiVO}_{4}$ of $0.0188 \mathrm{~min}^{-1}$ and $0.0487 \mathrm{~min}^{-1}$, respectively, as shown in Figure 5. The $k_{\text {app }}$ of $0.25 \mathrm{~mol} \% \mathrm{Au} / \mathrm{BiVO}_{4}$ was more than twice higher compared to pure $\mathrm{BiVO}_{4}$. The $k_{\text {app }}$ of oxalic degradation was also found to be higher than that of malonic acid $\left(k_{\text {app }}=0.0082 \mathrm{~min}^{-1}\right)$. Generally, photocatalytic mineralization rate is governed by both structural and functional properties of the target molecule.

In this work, the two acids used as the targeted substrates are dicarboxylic acid; therefore, functional characteristic could not be the main reason explaining the difference in rate constants. However, by considering the structures of these acids, oxalic acid $\left(\mathrm{C}_{2}\right)$ with shorter carbon chain length than malonic acid $\left(\mathrm{C}_{3}\right)$ could provide higher apparent rate constant. Our finding is in good agreement with that of Denny et al. [38]. Therein, a decrease in 50\% mineralization rate with 


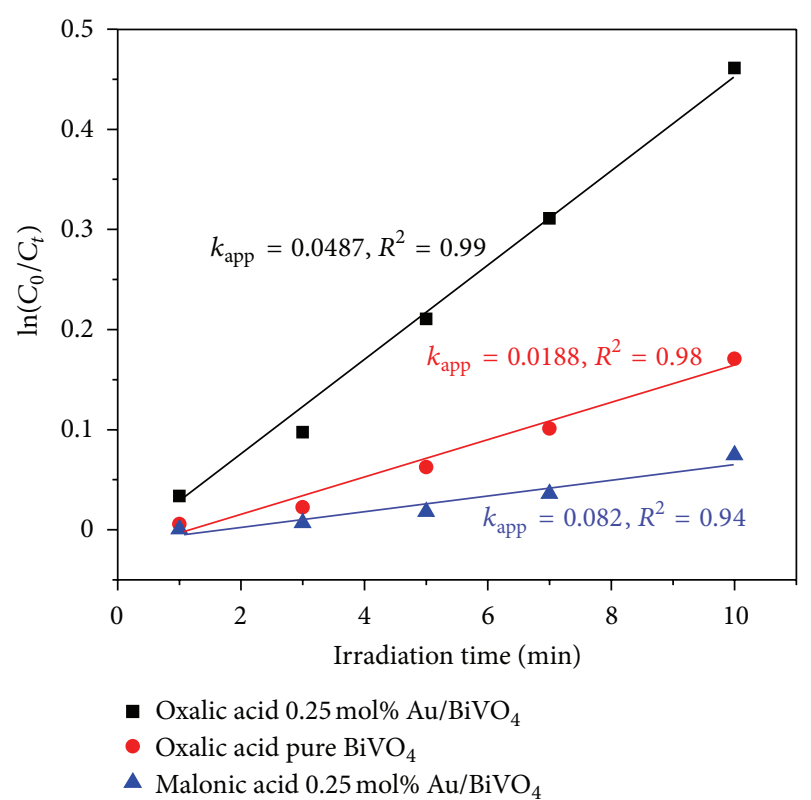

Figure 5: Plots of $\ln \left(C_{0} / C_{t}\right)$ versus irradiation time for the mineralizations of oxalic acid over pure $\mathrm{BiVO}_{4}, 0.25 \mathrm{~mol} \% \mathrm{Au} / \mathrm{BiVO}_{4}$, and malonic acid over $0.25 \mathrm{~mol} \% \mathrm{Au} / \mathrm{BiVO}_{4}$.

increasing carbon chain length was observed and the authors ascribed this behavior to the increased complexity of the degradation mechanism of the longer chain hydrocarbons. Therefore, the decrease in $k_{\text {app }}$ observed in our study was likely attributed to an increase in carbon chain length of the targeted molecule. However, other factors including an increased steric hindrance effect, a decrease of the positive charge on the carbon of carboxyl group as increasing carbon chain length, thus making hydroxyl radical attraction more difficult may also have some contribution to the obtained apparent rate constant [38,39].

\section{Conclusion}

Significantly improved photocatalytic efficiency was observed upon loading pure monoclinic-scheelite $\mathrm{BiVO}_{4}$ with low concentrations of gold dopant (0.1-1.0 mol\%). Maximum apparent rate constant observed from $0.25 \mathrm{~mol} \% \mathrm{Au} / \mathrm{BiVO}_{4}$ was found to be more than twice higher compared to pure $\mathrm{BiVO}_{4}$. However, loading Au more than $0.25 \mathrm{~mol} \%$ was detrimental to the photocatalytic activity since excess $\mathrm{Au}$ atoms may act as charge recombination centers, resulting in a decrease of charge carrier lifetime and low photocatalytic performance. The initial apparent pseudo-first-order rate constants of $0.25 \mathrm{~mol} \% \mathrm{Au} / \mathrm{BiVO}_{4}$ were found to be 0.0487 and $0.0082 \mathrm{~min}^{-1}$ for the degradations of oxalic acid and malonic acid, respectively. By considering structures of the two acids, lower pseudo-first order rate constant obtained in the case of malonic acid degradation was likely due to an increased complexity of the degradation mechanism of the longer chain acid. However, the fact that an enhanced steric hindrance effect and a decrease of the positive charge on the carbon of carboxyl group may affect the observed rate constantly could not be neglected.

\section{Acknowledgments}

The authors gratefully acknowledge the financial support from Thailand Graduate Institute of Science and Technology (TGIST) and The National Science and Technology Development Agency (NSTDA) to Kanlaya Pingmuang; the Research, Development and Engineering (RD\&E) fund through the National Nanotechnology Center (NANOTEC), NSTDA, Thailand (P-11-00982), for Chiang Mai University to Burapat Inceesungvorn; the National Research University Project under Thailand's Office of the Higher Education Commission, the Graduate School and Faculty of Science (Chiang Mai University) and the NANOTEC, NSTDA, Ministry of Science and Technology, Thailand, through its program of Center of Excellence Network. The authors would like to thank Mr. Ekkapong Kuntarak for his help in spectroscopy measurements.

\section{References}

[1] G. Li, J. C. Yu, J. Zhu, and Y. Cao, "Hierarchical mesoporous grape-like titania with superior recyclability and photoactivity," Microporous and Mesoporous Materials, vol. 106, no. 1-3, pp. 278-283, 2007.

[2] J. C. Yu, L. Zhang, Z. Zheng, and J. Zhao, "Synthesis and characterization of phosphated mesoporous titanium dioxide with high photocatalytic activity," Chemistry of Materials, vol. 15, no. 11, pp. 2280-2286, 2003.

[3] W. Y. Teoh, R. Amal, L. Mädler, and S. E. Pratsinis, "Flame sprayed visible light-active $\mathrm{Fe}-\mathrm{TiO}_{2}$ for photomineralisation of oxalic acid," Catalysis Today, vol. 120, no. 2, pp. 203-213, 2007.

[4] Y. Zhou, K. Vuille, A. Heel, B. Probst, R. Kontic, and G. R. Patzke, "An inorganic hydrothermal route to photocatalytically active bismuth vanadate," Applied Catalysis A, vol. 375, no. 1, pp. 140-148, 2010.

[5] A. Kudo, K. Ueda, H. Kato, and I. Mikami, "Photocatalytic $\mathrm{O}_{2}$ evolution under visible light irradiation on $\mathrm{BiVO}_{4}$ in aqueous $\mathrm{AgNO}_{3}$ solution," Catalysis Letters, vol. 53, no. 3-4, pp. 229-230, 1998.

[6] S. Kohtani, J. Hiro, N. Yamamoto, A. Kudo, K. Tokumura, and R. Nakagaki, "Adsorptive and photocatalytic properties of Agloaded $\mathrm{BiVO}_{4}$ on the degradation of 4-n-alkylphenols under visible light irradiation," Catalysis Communications, vol. 6, no. 3, pp. 185-189, 2005.

[7] J. Liu, H. Wang, S. Wang, and H. Yan, "Hydrothermal preparation of $\mathrm{BiVO}_{4}$ powders," Materials Science and Engineering $B$, vol. 104, no. 1-2, pp. 36-39, 2003.

[8] R. W. Hess, "Pigmentary bright primrose yellow monoclinic bismuth vanadate and processes for the preparation thereof," U.S. Patent no 4115142, 1978.

[9] K. A. Kudo and Y. Miseki, "Heterogeneous photocatalyst materials for water splitting," Chemical Society Reviews, vol. 38, no. 1, pp. 253-278, 2009.

[10] S. Kohtani, M. Tomohiro, K. Tokumura, and R. Nakagaki, "Photooxidation reactions of polycyclic aromatic hydrocarbons over pure and Ag-loaded $\mathrm{BiVO}_{4}$ photocatalysts," Applied Catalysis B, vol. 58, no. 3-4, pp. 265-272, 2005. 
[11] L. Ge, "Novel visible-light-driven $\mathrm{Pt} / \mathrm{BiVO}_{4}$ photocatalyst for efficient degradation of methyl orange," Journal of Molecular Catalysis A, vol. 282, no. 1-2, pp. 62-66, 2008.

[12] A. Zhang and J. Zhang, "Characterization and photocatalytic properties of $\mathrm{Au} / \mathrm{BiVO}_{4}$ composites," Journal of Alloys and Compounds, vol. 491, no. 1-2, pp. 631-635, 2010.

[13] Y. K. Kho, W. Y. Teoh, A. Iwase et al., "Flame preparation of visible-light-responsive $\mathrm{BiVO}_{4}$ oxygen evolution photocatalysts with subsequent activation via aqueous route," ACS Applied Materials \& Interfaces, vol. 3, no. 6, pp. 1997-2004, 2011.

[14] X. Zhang, Z. Ai, F. Jia, L. Zhang, X. Fan, and Z. Zou, "Selective synthesis and visible-light photocatalytic activities of $\mathrm{BiVO}_{4}$ with different crystalline phases," Materials Chemistry and Physics, vol. 103, no. 1, pp. 162-167, 2007.

[15] S. S. Dunkle, R. J. Helmich, and K. S. Suslick, "BiVO ${ }_{4}$ as a visiblelight photocatalyst prepared by ultrasonic spray pyrolysis," The Journal of Physical Chemistry C, vol. 113, no. 28, pp. 11980-11983, 2009.

[16] A. Kudo, K. Omori, and H. Kato, "A novel aqueous process for preparation of crystal form-controlled and highly crystalline $\mathrm{BiVO}_{4}$ powder from layered vanadates at room temperature and its photocatalytic and photophysical properties," Journal of the American Chemical Society, vol. 121, no. 49, pp. 11459-11467, 1999.

[17] A. R. Lim, S. H. Choh, and M. S. Jang, "Prominent ferroelastic domain walls in $\mathrm{BiVO}_{4}$ crystal," Journal of Physics, vol. 7, no. 37, pp. 7309-7323, 1995.

[18] L. Zhang, D. Chen, and X. Jiao, "Monoclinic structured $\mathrm{BiVO}_{4}$ nanosheets: hydrothermal preparation, formation mechanism, and coloristic and photocatalytic properties," Journal of Physical Chemistry B, vol. 110, no. 6, pp. 2668-2673, 2006.

[19] L. Ge, "Novel $\mathrm{Pd} / \mathrm{BiVO}_{4}$ composite photocatalysts for efficient degradation of methyl orange under visible light irradiation," Materials Chemistry and Physics, vol. 107, no. 2-3, pp. 465-470, 2008.

[20] B. Zhou, X. Zhao, H. Liu, J. Qu, and C. P. Huang, "Synthesis of visible-light sensitive $\mathrm{M}-\mathrm{BiVO}_{4}(\mathrm{M}=\mathrm{Ag}, \mathrm{Co}$, and $\mathrm{Ni})$ for the photocatalytic degradation of organic pollutants," Separation and Purification Technology, vol. 77, no. 3, pp. 275-282, 2011.

[21] S. W. Cao, Z. Yin, J. Barber, F. Y. C. Boey, S. C. J. Loo, and C. Xue, "Preparation of $\mathrm{Au}-\mathrm{BiVO}_{4}$ heterogeneous nanostructures as highly efficient visible-light photocatalysts," ACS Applied Materials \& Interfaces, vol. 1, no. 4, pp. 418-423, 2012.

[22] M. Long, J. Jiang, Y. Li, R. Cao, L. Zhang, and W. Cai, "Effect of gold nanoparticles on the photocatalytic and photoelectrochemical performance of $\mathrm{Au}$ modified $\mathrm{BiVO}_{4}$," Nano-Micro Letters, vol. 3, no. 3, pp. 171-177, 2011.

[23] J. Berlan, F. Trabelsi, H. Delmas, A. M. Wilhelm, and J. F. Petrignani, "Oxidative degradation of phenol in aqueous media using ultrasound," Ultrasonics Sonochemistry, vol. 1, no. 2, pp. S97-S102, 1994.

[24] W. Bian, X. Song, D. Liu, J. Zhang, and X. Chen, "The intermediate products in the degradation of 4-chlorophenol by pulsed high voltage discharge in water," Journal of Hazardous Materials, vol. 192, no. 3, pp. 1330-1339, 2011.

[25] C. M. Du, J. H. Yan, and B. G. Cheron, "Degradation of 4chlorophenol using a gas-liquid gliding arc discharge plasma reactor," Plasma Chemistry and Plasma Processing, vol. 27, no. 5, pp. 635-646, 2007.

[26] J. Tauc, R. Grigorovici, and A. Vancu, "Optical properties and electronic structure of amorphous germanium," Physica Status Solidi B, vol. 15, no. 2, pp. 627-637, 1966.
[27] M. Abdullah, G. K. C. Low, and R. W. Matthews, "Effects of common inorganic anions on rates of photocatalytic oxidation of organic carbon over illuminated titanium dioxide," The Journal of Physical Chemistry, vol. 17, no. 94, pp. 6820-6825, 1990.

[28] J. Yu, Y. Zhang, and A. Kudo, "Synthesis and photocatalytic performances of $\mathrm{BiVO}_{4}$ by ammonia co-precipitation process," Journal of Solid State Chemistry, vol. 182, no. 2, pp. 223-228, 2009.

[29] L. Ge, "Synthesis and characterization of novel visible-lightdriven $\mathrm{Pd} / \mathrm{BiVO}_{4}$ composite photocatalysts," Materials Letters, vol. 62, no. 6-7, pp. 926-928, 2008.

[30] P. V. Suraja, N. N. Binitha, Z. Yaakob, and P. P. Silija, "Preparation and characterization of nano gold supported over montmorillonite clays," IOP Conference Series, vol. 17, no. 1, Article ID 012019, 2011.

[31] M. S. Nasir and H. Nur, "Gold nanoparticles embedded on the surface of polyvinyl alcohol laye," Journal of Fundamental Sciences, vol. 4, pp. 245-252, 2008.

[32] M. A. Butler, "Photoelectrolysis and physical properties of the semiconducting electrode $\mathrm{WO}_{2}$," Journal of Applied Physics, vol. 8, no. 44, pp. 1914-1920, 1977.

[33] X. Meng, L. Zhang, H. Dai, Z. Zhao, R. Zhang, and Y. Liu, "Surfactant-assisted hydrothermal fabrication and visiblelight-driven photocatalytic degradation of methylene blue over multiple morphological $\mathrm{BiVO}_{4}$ single-crystallites," Materials Chemistry and Physics, vol. 125, no. 1-2, pp. 59-65, 2011.

[34] Z. Zhang, C. C. Wang, R. Zakaria, and J. Y. Ying, "Role of particle size in nanocrystalline $\mathrm{TiO}_{2}$-based photocatalysts," The Journal of Physical Chemistry B, vol. 52, no. 102, pp. 10871-10878, 1998.

[35] D. Beydoun, R. Amal, G. Low, and S. McEvoy, "Role of nanoparticles in photocatalysis," Journal of Nanoparticle Research, vol. 1, no. 4, pp. 439-458, 1999.

[36] K. V. Kumar, K. Porkodi, and F. Rocha, "LangmuirHinshelwood kinetics: a theoretical study," Catalysis Communications, vol. 1, no. 9, pp. 82-84, 2008.

[37] P. H. Chen and C. H. Jenq, "Kinetics of photocatalytic oxidation of trace organic compounds over titanium dioxide," Environment International, vol. 24, no. 8, pp. 871-879, 1998.

[38] F. Denny, J. Scott, K. Chiang, W. Y. Teoh, and R. Amal, "Insight towards the role of platinum in the photocatalytic mineralisation of organic compounds," Journal of Molecular Catalysis A, vol. 263, no. 1-2, pp. 93-102, 2007.

[39] W. Irawaty, D. Friedmann, J. Scott, and R. Amal, "Relationship between mineralization kinetics and mechanistic pathway during malic acid photodegradation," Journal of Molecular Catalysis A, vol. 335, no. 1-2, pp. 151-157, 2011. 

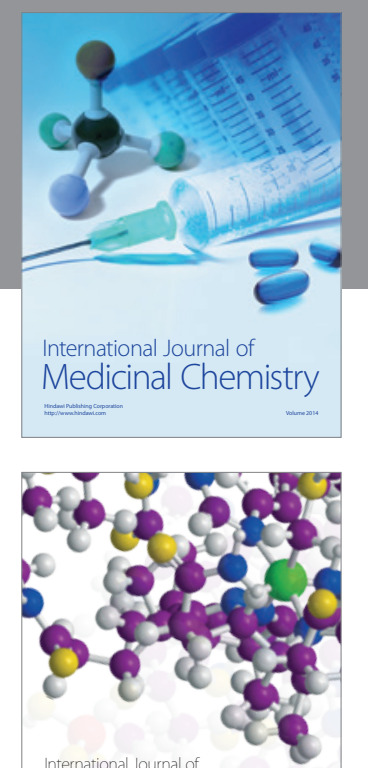

\section{Carbohydrate} Chemistry

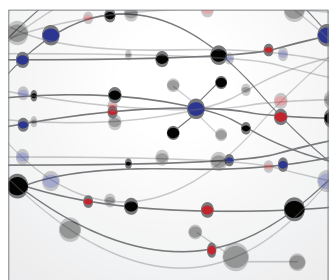

The Scientific World Journal
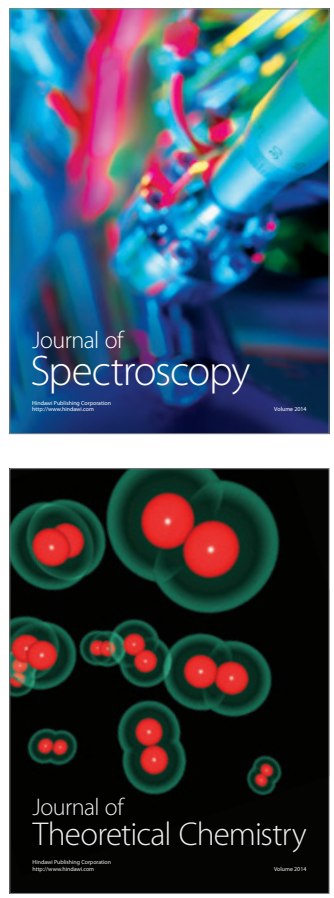
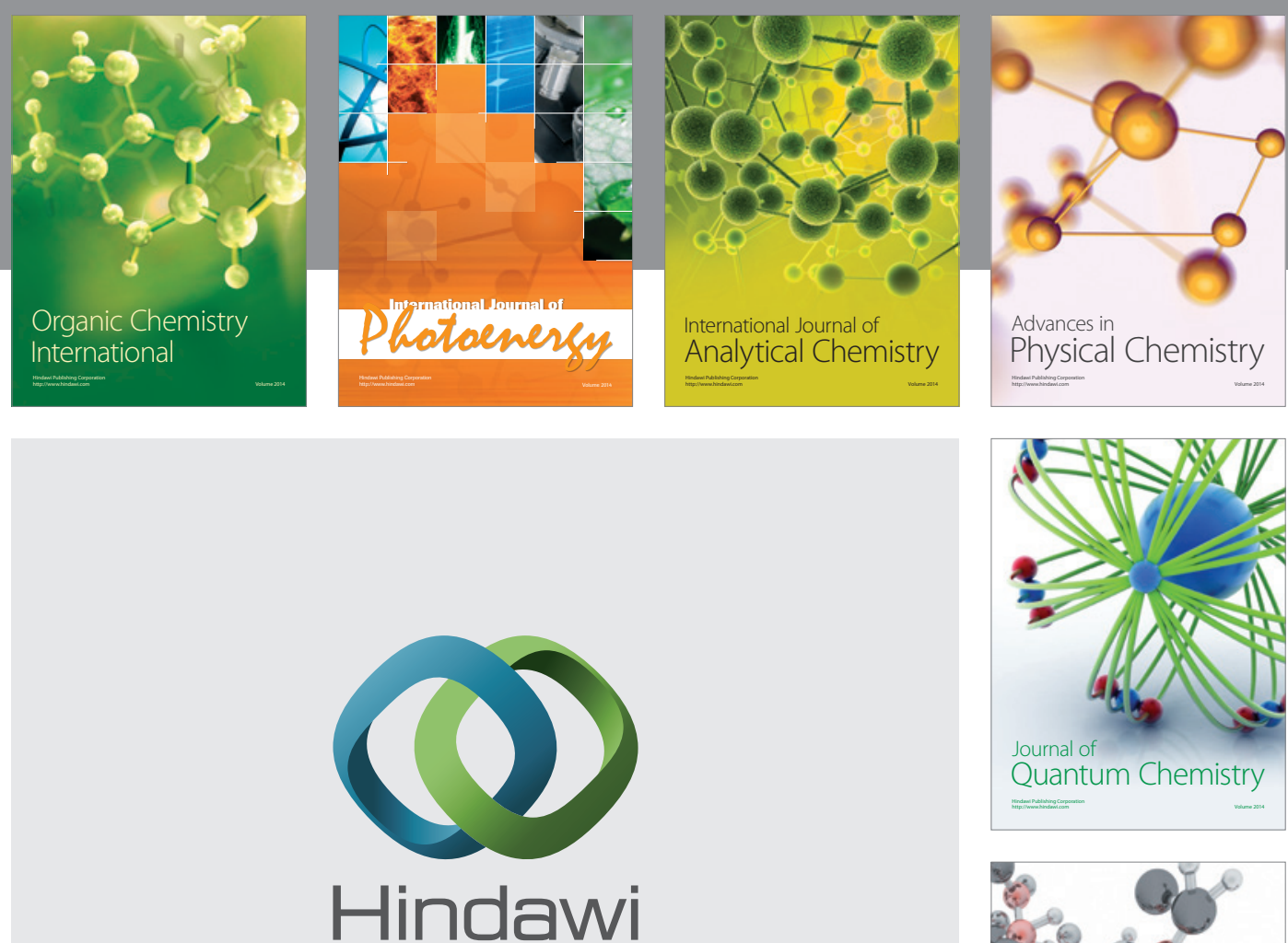

Submit your manuscripts at

http://www.hindawi.com

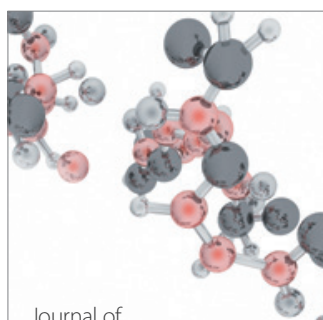

Analytical Methods

in Chemistry

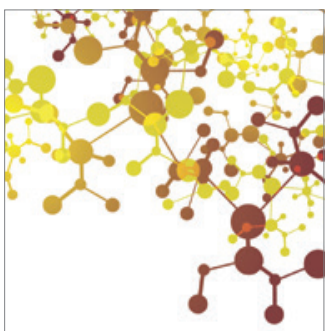

Journal of

Applied Chemistry

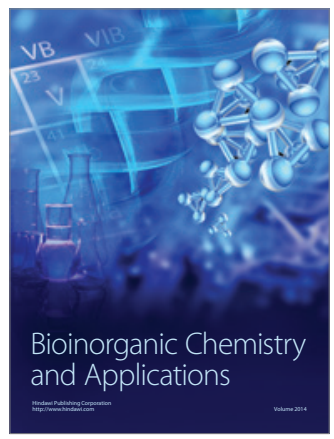

Inorganic Chemistry
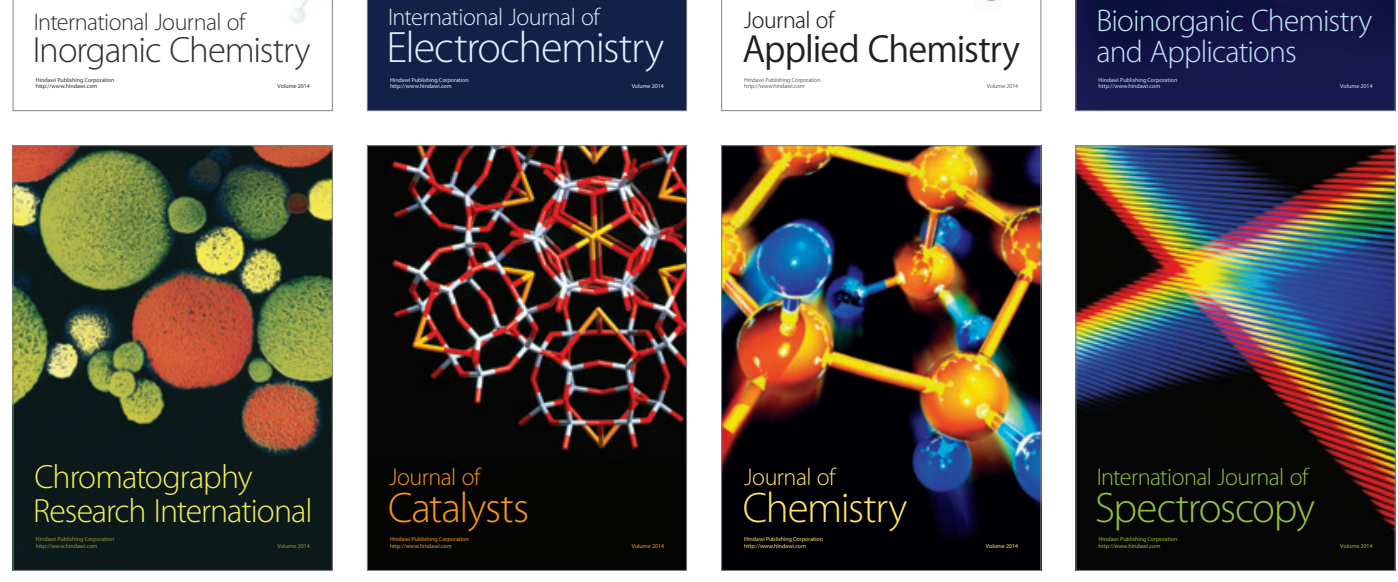